\title{
Investigation of Meandered Antenna for WLAN Application
}

\author{
Nivetha $\mathrm{S} \mathrm{B}^{\mathrm{a}, 1}$ and Bhuvaneswari $\mathrm{B}^{\mathrm{b}}$ \\ ${ }^{a} P G$ Scholar, Dept of ECE, Panimalar Engineering College, Chennai \\ ${ }^{\mathrm{b}}$ Professor, Dept of ECE, Panimalar Engineering College, Chennai
}

\begin{abstract}
In this paper patch antenna using coplanar waveguide structure is designed. The dimension of the antenna is $12 \times 22 \mathrm{~mm}$. The substrate material used is FR4 with thickness of $1.6 \mathrm{~mm}$. The dual band frequency is obtained by creating slot in the patch. Four slot is created in the patch.The frequency obtained for proposeddesign is 2.5 and $5.00 \mathrm{GHz}$. The gain obtained for proposed antenna is $2.8 \mathrm{dBi}$. The return loss obtained for proposed design is $-35 \mathrm{db}$ at $5 \mathrm{GHz}$ and $-34 \mathrm{~dB}$ at $2.5 \mathrm{GHzfrequency}$.The meander antenna with two arm is designed using normal ground structure .Single band resonance is obtained for meander antenna with two arm at the frequency of $5.7 \mathrm{GHz}$. The coplanar waveguide structure is chosen for dual band resonance and reduction in size.The designed antenna is used for WLAN application.
\end{abstract}

Keywords. Frequency, Return loss, Gain

\section{Introduction}

Microstrip antennas, consist of patch,groundplane and substrate.The patch is placed above the groundplane and substrate.The width and length of the groundplane and substrate is twice that of the patch .The compact dual band microstip antenna using coplanar waveguide is designed[1]. The excitation is obtained by matching the impedance that is by connecting $50 \mathrm{ohm}$ transmission line..Due to small size the microstrip antenna is used for biotelemetry applications[2]. The pacth is sepearted by substrate .The commonly used substrate material is FR4.The dielectric constant of the substrate material is 4.4.The thickness of the substrate material used for microstrip antenna is $1.6 \mathrm{~mm}$ The FF4 substrate is used due to ease of fabrication.Ultra wide band using notched antenna is designed[3]. The antenna operation is based on the thicker substrates.Based on the dimension of the substrate material it provides good efficiency and wider bandwidth. The inverted $\mathrm{F}$ microstrip antenna is used for GPS application[4].The reflection coefficient should be greater than $-20 \mathrm{~dB}$.The return loss obtained for ultra wideband antenna is $-25 \mathrm{~dB}$ [5Due to compact size the antenna is used for WLAN application[6].Tripple band resonance can be obtained using microstrip antenna [7].The impedance matching can be obtained using coplanar waveguide structure[8].The MIMO antenna is used for 5G cellular and Wi-Fi applications[9].The printed array antenna is used for heart attack detection[10].

\footnotetext{
${ }^{1}$ Nivetha S B ,PG Scholar, Department of ECE, Panimalar Engineering College, Chennai;

E-mail:sbnivetha97@gmail.com
} 


\section{Design Procedure}

Design calculation for patch

Step 1: Width Calculation(W)

$W=\frac{v 0}{2 f_{r}} \sqrt{\frac{2}{\epsilon_{r}+1}}(1)$

$\mathrm{W}=36.5 \mathrm{~mm}$

Operating frequency is $2.5 \mathrm{GHz}$

Step 2:Determination of effective dielectric constant:

Dielectric constant

$\epsilon_{\text {eff }}=\frac{\epsilon_{r}+1}{2}+\frac{\epsilon_{r}-1}{2}\left[1+12 \frac{h}{w}\right]^{-1 / 2}(3)$

$\epsilon_{\text {eff }}=6.27$

ii) Determination of $\Delta \mathrm{L}$

$\Delta L=0.412 h \frac{\left(\epsilon_{e f f}+0.3\right)\left(\frac{w}{h}+0.264\right)}{\left(\epsilon_{e f f}-0.258\right)\left(\frac{w}{h}+0.8\right)}(5)$

$\Delta L=0.72 \mathrm{~mm}(6)$

iii) Determination of length of thepatch

$L=\frac{1}{2 f_{r} \sqrt{\epsilon_{e f f} \sqrt{\mu_{0} \epsilon_{0}}}}-2 \Delta L(7)$

where,

$$
L=22.8 m m(8)
$$

' $\mathrm{f} 0$ ' is the operating frequency

' $\mathrm{W}$ ' is the width of patch

' $\mathrm{L}$ ' is the length of Patch

' $h$ ' is the height of patch

' $E \mathrm{r}$ ' is the dielectric constant

' $c$ ' is the speed of light: $3 \times 10^{8}$

\section{Proposed Design 1}

\section{1meander Antenna With Two Arm}

To reduce the size of the antenna the meander slot with two arm is designed using CST software. To further enhance the bandwidth of the resonance frequency the meander antenna with two arm is designed. The meander line antenna structure is choosen due to its compactness. The efficiency depends on the number of the turns. The frequency is shifted by varying the space of the arm .The length of the arm is reduced to 3/4.The operating frequency of the meander antenna is $5.56 \mathrm{GHz}$. The returnloss obtained is $-35 \mathrm{~dB}$ which is greater than meander slot with six arm. The bandwidth of the antenna can be expanded using air substrate. The bandwidth of the meander antenna with two arm is $120 \mathrm{MHz}$ which is greater than bandwidth of the patch antenna. 


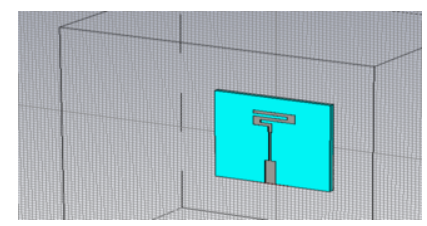

Figure 1. Meander antenna with two arm

\section{Design Of Slot Antenna Using Coplanar Waveguide Structure}

The patch antenna with slots is designed using coplanar waveguide structure .The first part is substrate the size of the substrate is .The substrate substance used is FR4.The thickness of the substrate is $1.6 \mathrm{~mm}$. The second plate is patch the size of the patch is $12 \times 22 \mathrm{~mm}$. The patch is filled with PEC material .The thickness of the patch is $0.035 \mathrm{~mm}$. The $50 \mathrm{ohm}$ transmission line is connected to the patch forexcitation. The ground is reduced to half of the size of substrate andpatch. The gap to the ground and the patch is $2 \mathrm{~mm}$. The material used for ground is PEC.The thickness of the ground is $0.035 \mathrm{~mm}$. The distance between the feed and the ground is $0.4 \mathrm{~mm}$. The return loss obtained is $-17 \mathrm{~dB}$ at $2.5 \mathrm{GHz}$ and $-32 \mathrm{~dB}$ at $4.47 \mathrm{GHz}$ frequency.

\section{Proposed Design 2}

In the second design the width and length of the substrate is varied to .The width of the second slot is $1 \mathrm{~mm}$. The width of the fourth slot is $1 \mathrm{~mm}$. While changing the dimension the operating frequency is tuned and obtained better results at the frequency $2.5 \mathrm{GHz}$ and $5 \mathrm{GHz}$. When the dimension of substrate is changed returnloss greater than $-25 \mathrm{~dB}$ is obtained.The distance around ground and the patch is $2 \mathrm{~mm}$. The fabrics used for ground is PEC.The thickness of the ground is $0.035 \mathrm{~mm}$. The distance between the feed and the ground is $0.4 \mathrm{~mm}$. The return loss obtained is $-34 \mathrm{~dB}$ at $2.5 \mathrm{GHz}$ and $-34 \mathrm{db}$ at $5 \mathrm{GHz}$ frequency. The gain obtained is $2.8 \mathrm{~dB}$.

Table1. Dimensions of modified slot antenna

\begin{tabular}{|l|l|}
\hline Parameters & Dimensions \\
\hline Patch(W) & $12 \mathrm{~mm}$ \\
\hline Patch(L) & $22 \mathrm{~mm}$ \\
\hline Ground (W) & $11 \mathrm{~mm}$ \\
\hline Ground(L) & $9 \mathrm{~mm}$ \\
\hline Feed $(\mathrm{W})$ & $1.65 \mathrm{~mm}$ \\
\hline Feed(L) & $23 \mathrm{~mm}$ \\
\hline First slot(W) & $0.5 \mathrm{~mm}$ \\
\hline Firstt slot(L) & $4 \mathrm{~mm}$ \\
\hline Second slot (W) & $1 \mathrm{~mm}$ \\
\hline Second slot(L) & $2 \mathrm{~mm}$ \\
\hline Third slot(W) & $0.5 \mathrm{~mm}$ \\
\hline Third slot (L) & $3 \mathrm{~mm}$ \\
\hline Fourth slot(W) & $0.5 \mathrm{~mm}$ \\
\hline Fourth slot (L) & $5 \mathrm{~mm}$ \\
\hline
\end{tabular}




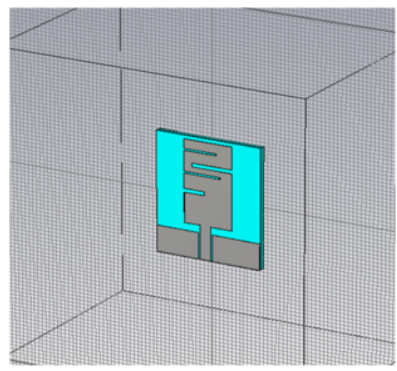

Figure 2. Modified Slot antenna design

\section{Results And Discussion}

The slot antenna using coplanar waveguide structure is designed using CST software.The reflection coefficient obtained for proposed design 1 is $-17 \mathrm{~dB}$ at $2.5 \mathrm{GHz}$ and $-32 \mathrm{~dB}$ at $4.47 \mathrm{GHz}$.Figure 5 shows the gain of slot antenna. The gain obtained is $1.785 \mathrm{~dB}$ for the frequency of $2.5 \mathrm{GHz}$.Figure 6 shows $\mathrm{S}_{11}$ of modified slot antenna the reflection obtained for proposed design 2 is $-34 \mathrm{~dB}$ at $2.5 \mathrm{GHz}$ and $-34 \mathrm{~dB}$ at $5 \mathrm{GHz}$ frequency the gain obtained for proposed design 2 is $2.8 \mathrm{~dB}$.

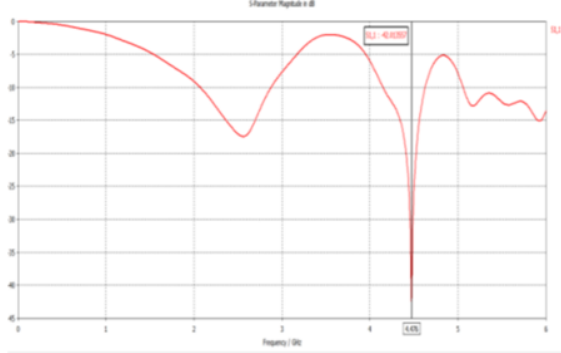

Figure 3. Reflection coefficient of slot antenna using CPW

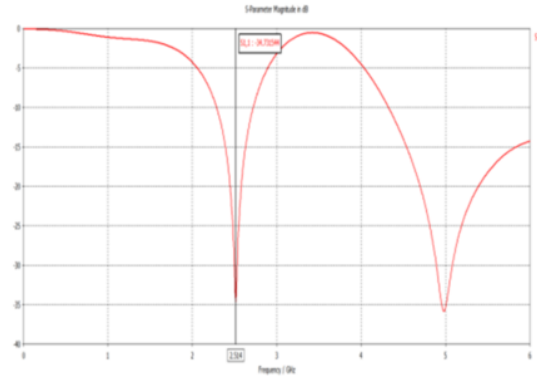

Figure 5. Reflection coefficiecent of modified slot antenna

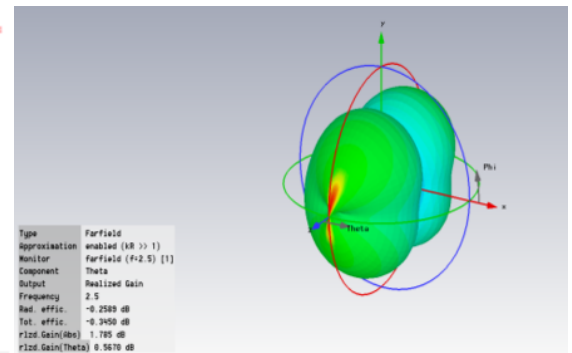

Figure 4. Gain of slot antenna

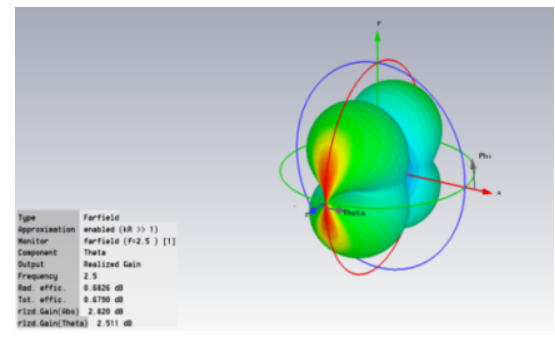

Figure 6. Gain of modified slot antenna

Table 2 shows comparison parameter of designed antenna the various parameters such as bandwidth,gain.VSWR and reflection coefficient is analyzed.The bandwidth obtained for proposed design is wider than proposed design 1.From the table it is obivious that modified slot antenna provides better performance than meander with two antenna and slot antenna[10]. 
Table 2. Comparison of different parameters of proposed design

\begin{tabular}{|l|l|l|l|}
\hline PARAMETERS & $\begin{array}{l}\text { MEANDER WITH } \\
\text { TWO ARM }\end{array}$ & SLOT ANTENNA & $\begin{array}{l}\text { MODIFIED SLOT } \\
\text { ANTENNA }\end{array}$ \\
\hline $\mathrm{S}_{11}(\mathrm{~dB})$ & -35 & $-17,-32$ & $-34,-34$ \\
\hline Bandwidth(MHz) & 120 & 33,108 & 230,672 \\
\hline $\begin{array}{l}\text { Centre } \\
\text { frequency }(\mathrm{GHz})\end{array}$ & 5.56 & $2.5,4.47$ & $2.5,5$ \\
\hline VSWR & 1.02 & $1.125,1.06$ & $1.06,1.06$ \\
\hline Gain(dB) & 5.27 & 1.785 & 2.82 \\
\hline
\end{tabular}

\section{Conclusion}

In this paper meander antenna and slot antenna using coplanar waveguide is designed using CST software.The results obtained for meander antenna with two arm is $-30 \mathrm{~dB}$ at the frequency of $5.7 \mathrm{GHz}$. The results obtained for slot antenna is $-17 \mathrm{~dB}$ at the frequency of $2.5 \mathrm{GHz}$ The design is modified and results obtained for this design is $34 \mathrm{dBathe}$ frequency of $2.5 \mathrm{GHz}$ and $-34 \mathrm{~dB}$ at the frequency of $5 \mathrm{GHz}$. The results are compared and analyzed. The results obtained for modified slot antenna is better compared to other antenna. Thus the designed antenna is used for WLAN application.

\section{References}

[1] K-Dong, F-S-Zhang, L-Chen, P-Zhu, Q-Zhang and Y-Zhu,A Compact Dual-band Planar Monopole Antenna for $2.4 / 5 \mathrm{GHz}$ WLAN Application. Proceedings of International Symposium on Signals, Systems and Electronics ,2010.

[2] Yijun Liu, Yifan Chen, Haili Lin, and Filbert H. Juwono,A Novel Differentially Fed Compact DualBand Implantable Antenna for Biotelemetry Applications. IEEE antennas and wireless propagation LETTERS, VOL. 15, 2016.

[3] Sheng Peng,HongxingZheng,Design of Coplanar-Waveguide-Feed Antenna .International Journal of Engineering Research \& Technology (IJERT) Vol. 4 Issue 07, July-2015.

[4] Meng-ShuangWang, Xiao-Qi Zhu, Yong-XinGuo.Miniaturized Dual-Band Circularly Polarized Quadruple Inverted-F Antenna for GPS Applications. IEEE antennas and wireless propagation letters, vol. 17 , no. 6 , june 2018 .

[5] Sanjeev Kumar Mishra, Rajiv Kumar Gupta, AvinashVaidya, and Jayanta Mukherjee .A Compact Dual-Band Fork-Shaped Monopole Antenna for Bluetooth and UWB Applications. IEEE ANTENNAS AND WIRELESS PROPAGATION LETTERS, VOL. 10, 2011.

[6] Hsien-Wen Liu, Sheng-Yu Lin, and Chang-Fa Yang .Compact Inverted-F Antenna With Meander Shorting Strip for Laptop Computer WLAN Applications. IEEE ANTENNAS AND WIRELESS PROPAGATION LETTERS, VOL. 10, 2011.

[7] Chow-Yen-Desmond Sim, Hsuan-Yu Chien, andChing-Her Lee.Dual-/Triple-Band Asymmetric Dipole Antenna for WLAN Operation in Laptop Computer.IEEEtransactions ON ANTENNAS AND PROPAGATION, VOL. 61, NO. 7, JULY 2013.

[8] Sang Y. Park ,Seon J. Oh , Jong K. park , and Jin S. Kim, Dual-Band Antenna for WLAN/UWB Applications.IEEE,2009.

[9] Rashid Saleem ,Muhammad Bilal, Hassan Tariq Chattha , Sabih Ur RehmanAnum Mushtaq1, And Muhammad FarhanShafique .An FSS Based Multiband MIMO System Incorporating 3D Antennas for WLAN/WiMAX/5G Cellular and 5G Wi-Fi Applications.IEEE,2019.

[10] Pranaya Krishna, C. Manoj Reddy, P. Srinivas Reddy and M. NeelaveniAmmal .Design of Printed Antenna for Heart Failure Detection.Research Journal of Medical Sciences,vol 10,(2016). 